\begin{tabular}{|l|l|l|l|l|}
\hline Cuadernos de Investigación Geográfica & 2012 & N $^{\circ} 38(2)$ & pp. 123-145 & ISSN 0211-6820 \\
\hline
\end{tabular}

(C) Universidad de La Rioja

\title{
EL PAPEL DEL RELIEVE EN LA DEFINICIÓN DE UNIDADES DE PAISAJE. EL CASO DE MUNTANYES D'ORDAL (BARCELONA)
}

\author{
D. SERRANO GINÉ* \\ Departamento de Geografía. Facultad de Turismo y Geografía. \\ Universitat Rovira i Virgili. Tarragona.
}

\begin{abstract}
RESUMEN. En este trabajo se reflexiona acerca de la importancia del relieve en el paisaje y, particularmente, en la definición de unidades de paisaje. Se establece una clasificación que diferencia tres perspectivas de trabajo, según el tratamiento metodológico con el que se aborde el relieve. Finalmente se desarrolla una metodología propia de los inventarios territoriales con base geomorfológica, que se aplica a Muntanyes d'Ordal (Barcelona). Los resultados se acompañan de una cartografía detallada, donde se señalan las 36 unidades identificadas, y de una sucinta reflexión sobre las bondades y dificultades del método empleado.
\end{abstract}

The role of the relief in the definition of landscape units. The case of Muntanyes D'Ordal

ABSTRACT. This paper deals on the importance of the relief in the landscape and, particularly, in the definition of landscape units. It establishes a classification that differentiates three approaches, according to the relief methodological treatment. Finally it develops a methodology according to surveys with geomorphological basis that is applied to Muntanyes d'Ordal (Barcelona). The results are completed with detailed cartography, where 36 units are identified, and with a succinct reflection on the goodness and difficulties of the employed method.

Palabras clave: paisaje, inventario territorial, unidad de paisaje, unidad de relieve, Muntanyes d'Ordal.

Key words: landscape, land survey, landscape unit, relief landscape, Muntanyes d'Ordal.

Enviado el 15 de marzo de 2011 Aceptado el 25 de octubre de 2011

\footnotetext{
* Correspondencia: Departamento de Geografía. Facultad de Turismo y Geografía. Universitat Rovira i Virgili. Av. Joanot Martorell, 15, 43480 Vila-seca, Tarragona. E-mail: david.serrano@urv.cat
} 


\section{Introducción}

Tradicionalmente los estudios de paisaje, los trabajos regionales y, particularmente, aquellos ejercicios de tipo fisiognómico, han concedido una importancia especial a las cuestiones relacionadas con la estructura y caracterización del relieve. En este sentido son reveladoras las palabras del geólogo y geógrafo Marcel Chevalier, que aseguraba "tots els paisatges són geològics i geogràfics. Si sabem estudiar-los i comprendre'ls, ens diran millor que qualsevol descripción de mà de l'home la història de la regió considerada" (Chevalier, 1928), para más tarde añadir: "podem dir, d'una manera general, que tots els agents que han intervingut en la formació dels paisatges i els han donat llur fisomia especial, han concentrat llurs esforços vers dues modalitats ben definides, forma i color, que resumeixen i condensen tots els elements d'un paisatge; els quals, com veurem més endavant, són en gran part d'ordre geològic" (Chevalier, 1928).

Pocos años más tarde Hernández Pacheco inauguraba el curso académico de la Universidad de Madrid con una ponencia que llevaba por título El paisaje en general y las características del paisaje hispano (1934). En realidad se trataba de la culminación de distintos trabajos y conferencias articuladas en torno al estudio del paisaje y de la geología. Algunos de estos ejercicios habían gozado de especial atención, como es el caso de Síntesis fisiográfica y geológica de España o La geología y el paisaje, conferencia pronunciada en 1926 en la Residencia de Estudiantes de Madrid. Para el responsable de la Comisaría de Parques Nacionales el paisaje podía entenderse como "la manifestación sintética de las condiciones y circunstancias geológicas y fisiográficas que ocurren en un país" (Hernández Pacheco, 1934) y podía estudiarse atendiendo a "elementos componentes fundamentales", "complementarios" y "accesorios", en paisajes tan significativos como el Torcal de Antequera o la Ciudad Encantada de Cuenca.

A tenor de estas contribuciones resulta fácil destacar la importancia del relieve en el estudio del paisaje. Ello se debe principalmente al peso que la litología y la geomorfología poseen en la configuración de un territorio. Pero también, y de manera muy especial, al significado visual y la indiscutible impronta fisiognómica que el relieve desempeña en el paisaje: "ainsi, observé et perçu, le relief devient paysage, ou plus précisément une partie du paysage, le cas des paysages dont les composantes physiques sont uniquement de nature géomorphologique étant relativement rares" (Reynard, 2005). Esta participación se concreta en la forma y posición de la topografía, los materiales constituyentes, las diferentes alturas, orientaciones, pendientes, cromatismos, geoformas, procesos y agentes geomorfológicos derivados, que de manera manifiesta influencian en el resto de elementos que conforman el paisaje y marcan de manera explícita su carácter (Knight, 2000; Gray, 2004). Todo ello evidencia la importancia de la dimensión espacial de lo geomorfológico, entendida de la manera más amplia posible, así como la validez de su participación en trabajos ambientales y de base territorial (Martín Duque, 2000).

Así pues, el valor del relieve en la configuración del paisaje se debe fundamentalmente al peso que poseen las variables que lo constituyen, a su rol estructurador y su predominio visual, que lo incluyen e individualizan, al mismo tiempo, en el conjunto donde se encuentran: "Mais le relief peut-il se confondre avec le paysage? Si l'on consi- 
dère que pour qu'il y ait paysage, il faut que s'établisse une relation entre une portion de l'espace géographique et un observateur et que cette relation introduit une série de filtres perceptifs entre l'espace géographique et ce que nous appelons le paysage. Il participe bien sûr à la création de paysages, mais il n'est pas le paysage. C'est ce que nous avons appelé le paysage géomorphologique, que l'on pourrait définir comme « une portion du relief terrestre, vue, perçue (et parfois exploitée) par l'Homme »" (Reynard, 2004).

\section{Geomorfología y paisaje}

La definición y caracterización de un paisaje se realiza a partir del análisis y posterior síntesis de los distintos elementos que lo conforman (Bolòs, 1992). Existen numerosos trabajos que manifiestan la contribución del relieve en el paisaje. Según el protagonismo que se dispense a lo topográfico, esta participación da lugar a ejercicios donde el relieve se entiende como elemento condicionante, como elemento estructurador o como elemento definidor del estudio de paisaje.

\subsection{El relieve como elemento condicionante}

En determinados paisajes el relieve (o las distintas variables que lo conforman) posee un protagonismo tan manifiesto que no solo condiciona el resto de elementos del paisaje, sino que incluso condiciona la manera de abordar su estudio. En estos planteamientos de trabajo las cuestiones relacionadas con el relieve se encuentran primadas por encima del resto de elementos que configuran el paisaje. Desde esta perspectiva no es posible realizar zonificaciones bajo criterios de relieve, si bien la importancia e influencia del mismo es tan elevada que resulta totalmente indiscutible.

La participación del relieve en la formación de un paisaje es especialmente significativa cuando éste -el paisaje- se aprehende en clave evolutiva. El trabajo de Marthaler (2004) sobre el paisaje de la región suiza de Zermatt, donde se encuentra el pico Cervino, permite comprender de manera clara este hecho. En Zermatt se identifican materiales correspondientes a las cuatro eras geológicas de la Tierra, así como distintos episodios orogénicos y erosivos. El paisaje alpino actual es heredero de los procesos ocurridos desde el fin de la era primaria y particularmente desde los últimos 2.000 millones de años. Marthaler apunta que las actuaciones humanas sobre el paisaje son extraordinariamente recientes, y que incluso la impronta de los hielos cuaternarios debe entenderse como algo nuevo, que no representa más que el último episodio evolutivo del lugar. Desde esta óptica el peso del relieve en la constitución del paisaje es tan grande que a menudo eclipsa la participación de otros elementos, llegando a asimilar la parte más significativa del paisaje con la globalidad del mismo: "Cependant, lire et analyser un paysage natural alpin est une démarche complexe, car les événements géologiques qui ont permis de les construire ne sont pas lisibles dans une continuité spatiale" (Marthaler, 2004: 53). 
El estudio de Hansen Machín (1993) sobre la caldera de Bandama, en Gran Canaria, comprende el territorio articulado en torno al cono volcánico y la amplia caldera de Bandama, un aparato volcánico de indiscutible categoría y gran nitidez morfológica. Hansen señala los distintos ciclos eruptivos que organizan el conjunto así como los periodos erosivos que han modelado el lugar y han establecido su estructura territorial. Una vez definidos los condicionantes abióticos de mayor calado, el autor reseña otros elementos que terminan de caracterizar este ámbito, como es el caso del manto vegetal primigenio y el proceso de antropización, señalando distintos episodios de deforestación en la época hispánica hasta la desaparición de la masa arbolada en el siglo XIX, la masiva implantación del viñedo y el proceso urbanizador.

La influencia que el relieve ejerce en las dinámicas territoriales se hace patente, por ejemplo, en el estudio de Gómez Ortiz (2001) sobre el principado de Andorra. La contundencia del relieve en Andorra es claramente evidente, la altura media del país se halla entre los 1.900 y los 2.000 metros, y los desniveles y cambios topográficos son constantes. La fragilidad latente de este ámbito se materializa en la montaña como espacio tridimensional, donde altura, pendiente y volumen se conjugan en diversa proporción y condicionan de forma clara la estructura y funcionamiento del territorio. La evidencia del relieve como asiento del paisaje permite desgranar el patrimonio natural del Principado y, posteriormente, enlazarlo con la necesidad de actuaciones sostenibles y una conducta ética responsable.

\subsection{El relieve como elemento estructurador}

El relieve también puede considerarse como el elemento que articula el estudio que se lleva a cabo. Bajo esta perspectiva el relieve se entiende como estructurador del paisaje, no solo condicionando sino incluso supeditando el resto de elementos que lo conforman. Este planteamiento permite realizar zonificaciones en función de las características geomorfológicas de un territorio. La integración entre variables suele ser baja, tanto entre elementos de paisaje como entre variables de relieve. Ello comporta una cierta desvinculación respecto el conjunto donde se insieren, hecho que únicamente se supera cuando en los paisajes observados la topografía desempeña un papel evidente, o cuando la lectura del estudio se realiza en clave de geología física. Por esta misma razón la mayoría de estudios tienen validez a escalas medias y pequeñas, cuestión que resulta interesante si se tiene presente que este planteamiento, en un sentido amplio, puede entenderse como una regionalización morfológica, es decir, que usa el relieve como criterio rector. En consecuencia, las propuestas resultantes corresponden a estudios de tipo morfológico o fisiográfico, según la escuela de trabajo que se adopte.

El referente más consolidado de esta manera de hacer es la división morfológica de Fenneman para Estados Unidos, de 1916. En ella se distinguen delimitaciones en tres órdenes jerárquicos, siguiendo como criterio de definición las formas del relieve. Las unidades tienen validez a pequeña escala y se idean partiendo de una clasificación genética para las divisiones de mayor alcance, y topográfica para las de ámbito más reducido: “The segments here presented are of three orders, called respectively major divisions, provinces and 
sections". The basis of distinction among coordinate units is very much the same in all orders. On the whole it may be said that contrast in structure are stronger and more general between adjacent major divisions tan between adjacent divisions of lower orders. Naturally also, the degree of topographic homogeneity is greatest in the units of the lowest order, but the reasons for calling one area a major division and another a province or a section are not clearly defined" (Fenneman, 1916).

Knight (2000) deja de manifiesto la superioridad del relieve y, particularmente del relieve glaciar, en el paisaje de Irlanda. El autor subraya el peso fisiognómico y perceptual del relieve, que tanto puede manifestarse per se como en unión con otros elementos del paisaje: "The character of a single region may be perceived to be most strong where (1) landscape morphology has been controlled overwhelmingly by the effects of a single set of geomorphic process and (2) human imprint in the landscape, such as settlement patterns, closely reflects landscape characteristics, including topography, substrate/soil type and the distribution of water and mineral resources" (Knight, 2000), señalando que la evolución del paisaje tanto ocurre a escala humana como geológica. En el estudio se diferencian distintas regiones con una morfología homogénea, como los picos rocosos, las tierras de cultivo sobre drumlins o distintos tipos de costas y playas. Durante la caracterización de estos ámbitos se presta especial atención a la influencia de los procesos glaciales y periglaciales, así como al peso fisiognómico de las regionalizaciones propuestas y su influencia en el imaginario colectivo.

Desde una perspectiva de trabajo similar, García Quintana et al. (2004) demuestran la importancia de los factores geológicos en el paisaje de Guadalajara. Indican que el roquedo influye en el paisaje a través del color, la resistencia a la erosión y la medida y orientación de los cuerpos rocosos, y que todos estos factores ayudan a configurar dominios geológicos de ámbito regional, entendiendo estos dominios como áreas de distinta historia geológica, distinta estructura del roquedo y, por lo tanto, distinto paisaje. La estructura tectónica permite diferenciar formaciones de primer y segundo orden como, por ejemplo, las cordilleras y las cuencas sedimentarias, a partir de las cuales se aborda la acción del relieve sobre la vegetación y las actividades humanas, y viceversa.

\subsection{El relieve como elemento definidor}

Un último planteamiento de trabajo considera el relieve como el elemento que define la delimitación de unidades de paisaje. Esto es, señalando de manera precisa el límite entre ellas, clarificando los criterios de zonificación y permitiendo el uso de clasificaciones jerárquicas. Esta escuela de trabajo se caracteriza por determinar unidades tomando como referencia las distintas variables y parámetros que caracterizan el relieve, integrándolos según su participación en una clasificación escalar previamente definida y actuando de manera sistemática. Según la clasificación de Mitchell (1991), ésta es una propuesta centrada en el uso de parámetros y, en un sentido amplio, puede entenderse como un inventario territorial que usa el relieve como criterio rector. 
La propuesta de la Commonwealth Scientific and Industrial Research Organization (CSIRO) es muy sistemática. Según Christian y Stewart (1968) este método realiza delimitaciones a partir de la síntesis de la topografía, la geología y la geomorfología, por bien que también presta atención al clima, el suelo y la vegetación. Todo ello se integra en una unidad llamada "land", donde se contemplan las interacciones de los distintos elementos del medio: "the word land is used to refer to the land surface and all its characteristics of importance to man's existence and success. It is integration of all such factors rather than mere likeness or unlikeness in some of the more obvious observable characteristics which determine the similarity or dissimilarity of aerial subdivision in respect to land potential". Las unidades establecidas, en consecuencia, se caracterizan por sintetizar todos los elementos existentes.

Mitchell (1991) expone las características de este proceder y advierte la posibilidad de realizar clasificaciones de tipo coordinado (relativamente simples) y de tipo multivariado (relativamente complejas). Las primeras trabajan con un número limitado de elementos que generan una leyenda cerrada. Las segundas consideran que cada localización posee distintas propiedades, cada una de las cuales es percibida como una dimensión, de tal manera que las localizaciones son multidimensionales y su correlación únicamente es posible mediante formulaciones matemáticas que agrupen lugares según su posición espacial y su afinidad entre propiedades. El autor ejemplifica una clasificación de tipo coordinado donde se establecen unidades homogéneas a partir de la combinación de la altimetría, la precipitación y la geología de un sector del sureste de Inglaterra.

Con un planteamiento similar se encuentra el trabajo de Sánchez et al. (1995) para la isla de Gran Canaria, donde se realiza una división jerarquizada de la isla en "ambientes", "subambientes", "sistemas" y "unidades" a partir de: "la división del territorio en áreas que tienen en común determinadas características que las hacen diferentes de otras contiguas. La idea que subyace es considerar el clima, la litología, la morfogénesis del relieve, los procesos erosivos, la vegetación, los suelos y los usos antrópicos como los principales factores que explican la organización del paisaje de una determinada región" (Sánchez, 1995: 21). La clasificación correspondiente a "sistemas" se constituye por las formas que caracterizan el relieve a escala 1:50 000, delimitando porciones de terreno con características similares desde el punto de vista de la topografía, morfoestructura o morfodinámica. Esta categoría se subdivide en delimitaciones de rango inferior llamadas "subsistemas", donde se matizan las características definitorias del sistema donde se insieren. La propuesta resultante se establece a partir de la combinación de la geoforma dominante, el sustrato, la pendiente y, puntualmente, la génesis del relieve.

\section{El estudio del relieve como elemento definidor}

La importancia del relieve en configuraciones espaciales y, más específicamente, en trabajos aplicados o con vocación de generar inventarios territoriales, se ha puesto de manifiesto en distintas ocasiones (Chevalier, 1928; Hernández Pacheco, 1934 y 1955; Pedraza y Garzón, 1978; Tricart y Kilian, 1982; Garzón, 1988; Mitchell, 1991; Martín Duque, 2000; Gray, 2004). Nuestra propuesta de trabajo se encuentra en esta misma 
dirección. El objetivo es identificar, caracterizar y cartografiar las unidades de relieve que definen Muntanyes d'Ordal, siguiendo siempre un planteamiento de trabajo en la línea de los inventarios territoriales con base gemorfológica.

\subsection{Método de trabajo}

La realización del estudio ha partido de una consulta bibliográfica inicial seguida de un exhaustivo trabajo de campo y de un posterior trabajo de gabinete. Durante el trabajo de campo ha resultado de gran utilidad el uso de una ficha normalizada, que ha permitido colectar información de manera sistemática. Sin llegar a la complejidad de inventario de trabajos como los de Serrano y González Trueba (2005) o Reynard (2006), en ella se han observado datos generales de localización e identificación y datos sobre la litología, la forma del relieve predominante, formas hidrográficas, depósitos de materiales, tipo de modelado y presencia de geoformas de distribución puntual. Se han distinguido seis grandes grupos de sustrato, cinco grandes formas de relieve, cuatro posibles grados de pendiente para laderas y cinco familias de geoformas, aparte de una categoría abierta correspondiente a posibles observaciones de interés. Para su confección han sido provechosos los trabajos de Tricart (1976) y de Peña Monné (1997) sobre cartografía geomorfológica, así como las indicaciones del Ministerio de Medio Ambiente (2004) para la clasificación de pendientes y la descripción de formas del relieve.

En el tratamiento de los datos inventariados se han seguido los siguientes pasos:

a) Análisis de la información colectada, prestando atención a la morfoestructura, la litología, la geomorfología y las geoformas detectadas, así como otra información de carácter hidrográfico, edáfico o paisajístico que pudiera resultar de utilidad.

b) Delimitación de las unidades con validez a escala 1:20 000. Este proceso, que ha resultado ser harto delicado, se ha basado en la búsqueda de homogeneidades de los datos recogidos, respetando siempre una clara lógica escalar. En primer lugar se han realizado agrupaciones según su litología para posteriormente clasificarlas según la forma de relieve en que se presentaban. Siguientemente se han caracterizado las unidades delimitadas, hecho que ha generado un tercer nivel de análisis donde se ha distinguido la variable que mejor cualificaba la unidad; usualmente esta variable ha sido la pendiente, seguida de los procesos y el cromatismo de cada zonificación.

c) Cumplimentación de una ficha para cada una de las unidades establecidas, donde se han especificado las particularidades de cada delimitación, puesto que una unidad puede concretarse en más de una delimitación. Para esta fase ha resultado imprescindible la colecta de aquellas geoformas e información diversa de carácter puntual que, a diferencia de los anteriores datos, no presentaban carácter continuo sino discreto.

d) Cartografiado y tratamiento estadístico de la información generada. 
De esta manera se han delimitado, en primer lugar, y se han caracterizado, en segundo lugar, unidades con características similares desde el punto de vista de la topografía, la morfoestructura e, indirectamente, la morfodinámica, destacando particularmente aquellos aspectos geológicos y geomorfológicos de mayor peso en la configuración del paisaje. Finalmente la información obtenida se ha cartografiado. Durante todo el proceso ha resultado de gran utilidad el uso de un sistema de información geográfica, que ha permitido gestionar distintas capas de información, crear un modelo digital del terreno, obtener valores de pendiente y métricas de gran fiabilidad, así como generar cartografía temática.

Finalmente conviene señalar el elevado grado de síntesis de las unidades delimitadas ya que, a escala 1: 20 000, las zonificaciones propuestas recogen información topográfica, litológica y geomorfológica que, en un sentido amplio, permiten tipificar el relieve desde el punto de vista de la caracterización del paisaje.

\section{Aplicación metodológica}

Muntanyes d'Ordal es un ámbito de baja montaña emplazado en el sector central del sistema costero catalán, a escasos kilómetros de la ciudad de Barcelona y en el seno de su región metropolitana. El área de estudio alcanza poco más de $15.000 \mathrm{Ha}$ distribuidas en trece municipios que albergan a prácticamente 99.000 habitantes, concentrados principalmente en urbanizaciones residenciales de baja densidad (fig. 1).

El conjunto destaca por la compartimentación del relieve y por su evidente carácter montuoso; de hecho, las fallas ocupadas por los ríos Anoia y Llobregat marcan un límite nítido entre el área montañosa y los sectores llanos adyacentes, como la depresión del Penedès o el delta del Llobregat. A pesar de que las alturas máximas son modestas (únicamente en puntos concretos se supera la cota de los 600 metros), la fragmentación y rugosidad del relieve son notables y, ciertamente, influencian las actividades humanas y la ocupación del suelo. En este sentido la ocupación mayoritaria queda estructurada por formaciones vegetales de tipo mediterráneo y por algunos campos de cultivo, si bien las clases de más impronta visual son aquellas de carácter antrópico, como es el caso de sectores residenciales, polígonos industriales y logísticos o infraestructuras viarias (Paül y Serrano, 2005). En lo que atiende a figuras de protección, cabe decir que en el sector se distinguen tres áreas disjuntas reconocidas por el Pla d'Espais d'Interès Natural de la Generalitat de Cataluña que, a partir de 2007 quedan reforzadas por el LIC Serres del Litoral Central, de la Red Natura 2000.

A rasgos generales hay que entender este sector como un área particularmente sensible desde el punto de vista ambiental. Ello se debe, por una parte, a su inclusión en un contexto periurbano, con las presiones y condicionantes que ello comporta, y, por otra parte, a la fragilidad e inestabilidad propia de los relieves montañosos que, aunque modestos, son una constante del lugar (fig. 2). 


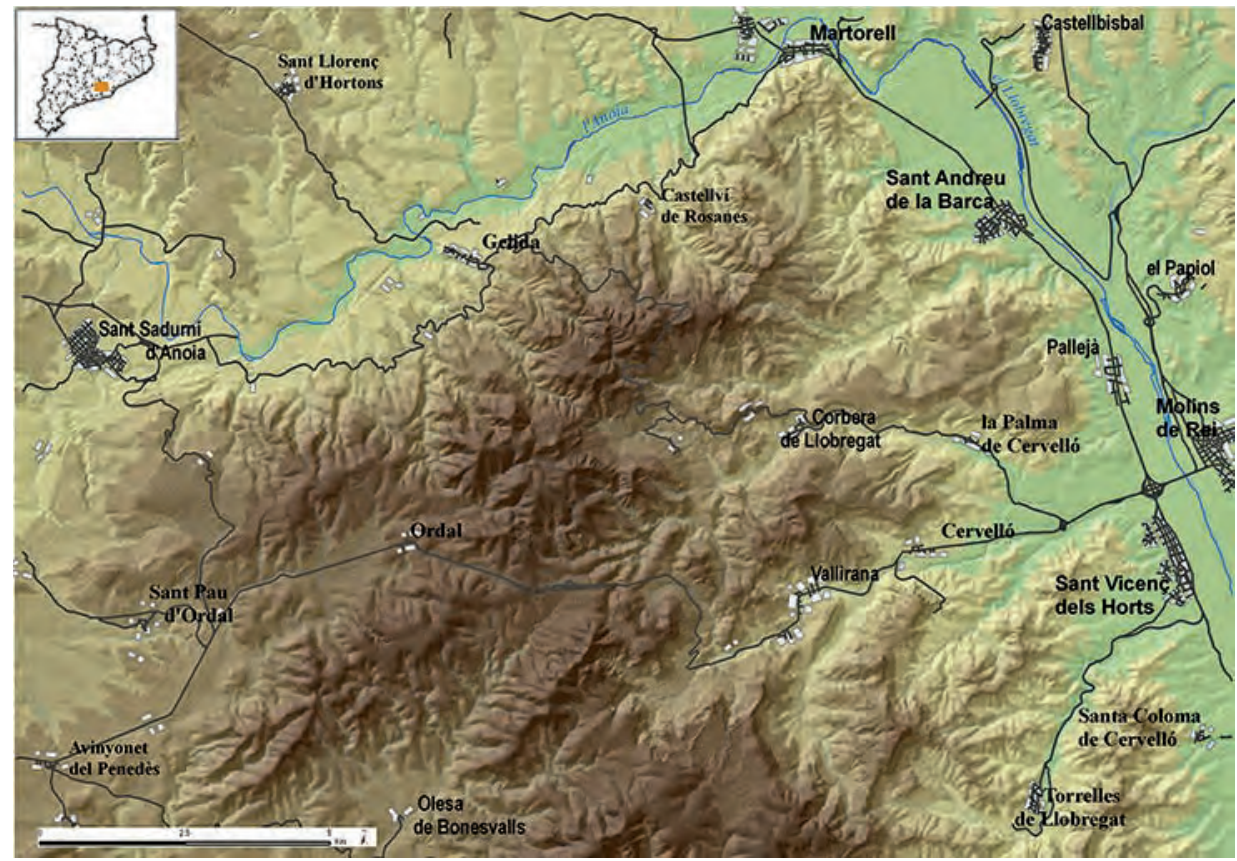

Figura 1. Localización de Muntanyes d'Ordal.

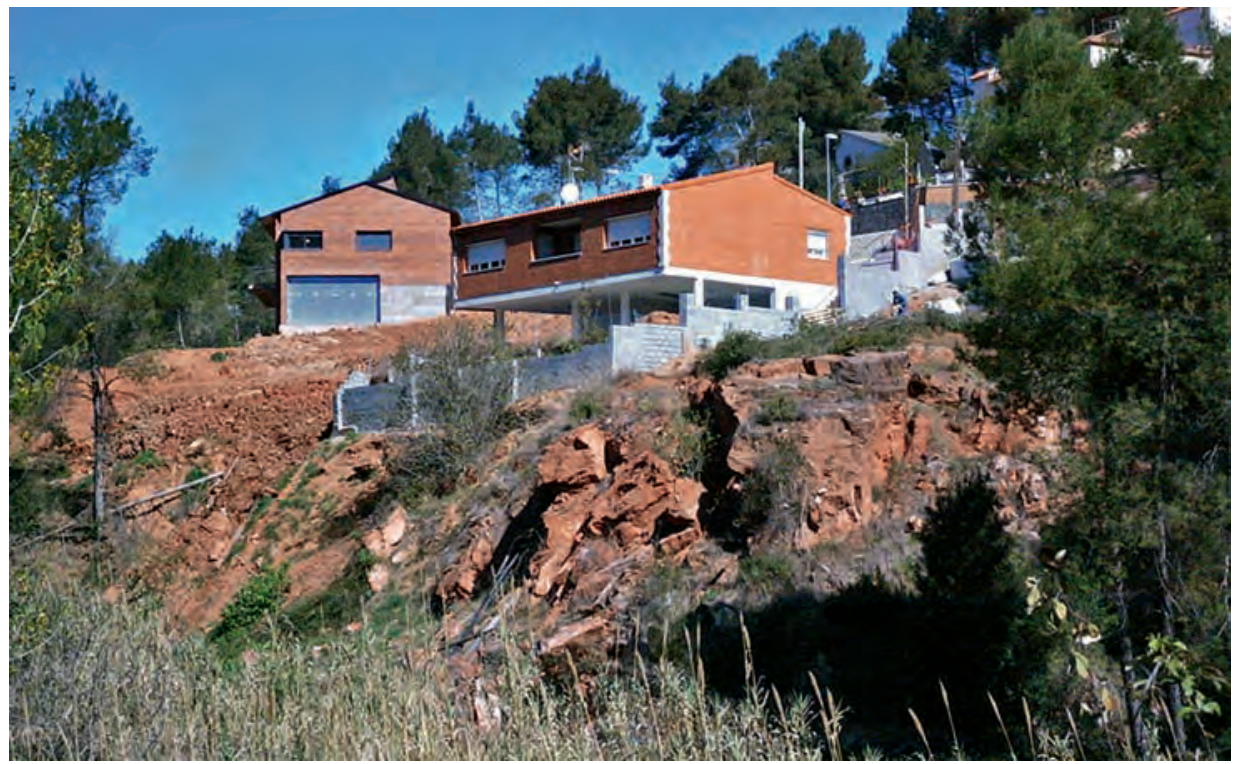

Figura 2. La urbanización y posterior edificación de algunos sectores de Muntanyes d'Ordal no siempre se ha realizado de la manera más correcta posible. En la imagen, urbanización Can Negre, Corbera de Llobregat. 


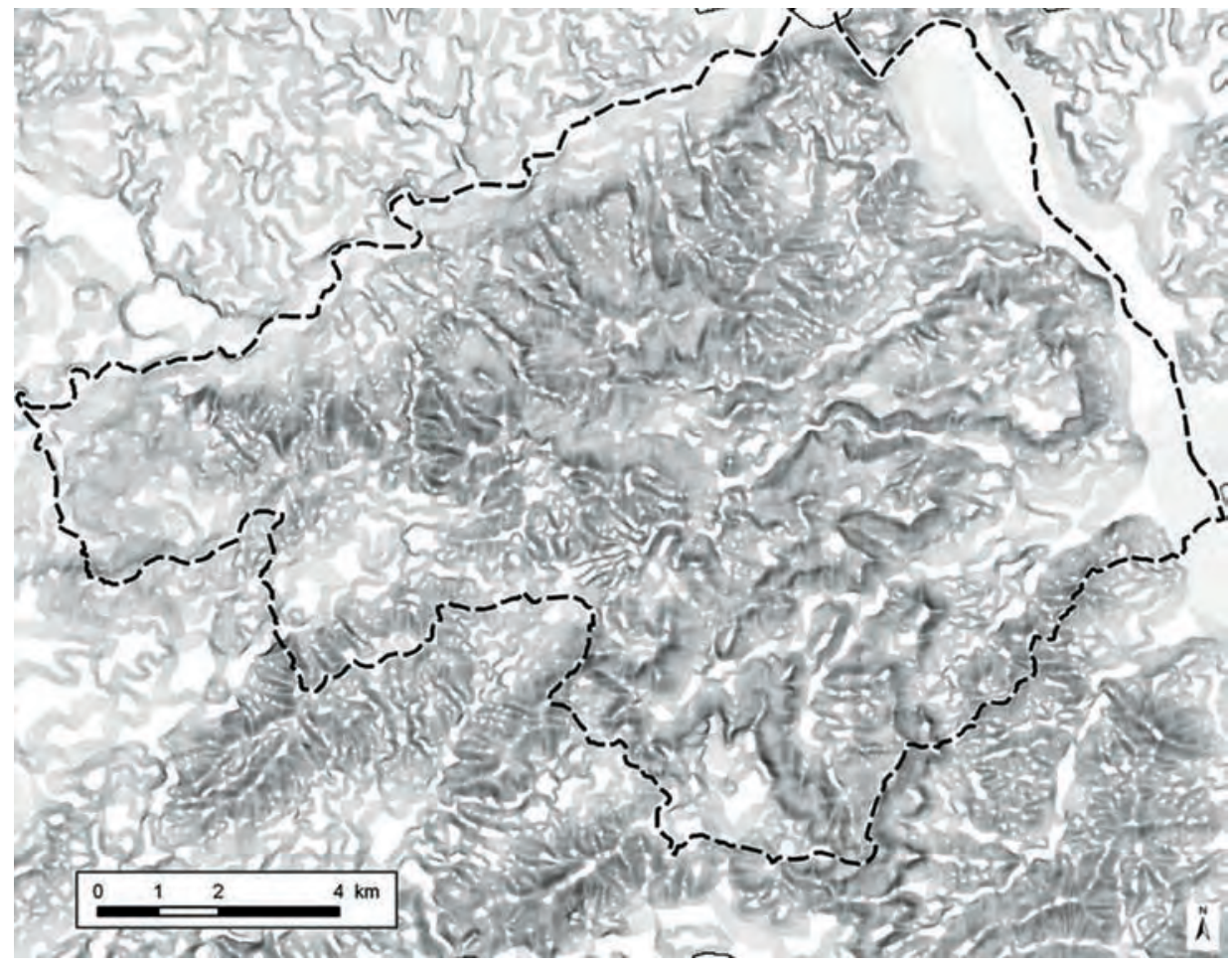

Figura 3. Rugosidad del relieve. Los valores más quebrados se representan en tonalidades más oscuras, mientras que los más dóciles aparecen en coloraciones blanquecinas.

\subsection{Contexto geomorfológico}

El relieve del área de estudio se organiza alrededor de Puig d'Agulles (653.1m), punto central y de mayor altitud del sector. En torno a Puig d'Agulles se disponen distintas sierras de menor entidad que, individualizadas en interfluvios, pierden altura y envergadura progresivamente, hasta quedar interrumpidas por las fallas del Anoia y el Llobregat, por el norte y el este, y confundirse con los relieves de Garraf y de Olèrdola por el sur y el oeste. De tal manera, a vista de pájaro, la disposición del relieve se asemeja a la de una gavilla de sierras anudadas por el centro, que toman direcciones excéntricas relativamente nítidas y fáciles de describir (fig. 3).

La estructura de Muntanyes d'Ordal comienza a configurarse a principios del Mioceno, como consecuencia de los cambios isostáticos producidos a final del Oligoceno en la adyacente depresión del Penedès. En esta época la cubeta del Penedès, y con ella también los sectores circundantes, se elevaron ligeramente hacia el noreste y bascularon hacia el sureste para, posteriormente a principios del Mioceno, terminar ensanchándose y creciendo en dimensión. Según Noel Llopis Lladó (1947), este esfuerzo derivó en grandes fracturas longitudinales con dirección NE-SW que favorecieron una transgre- 


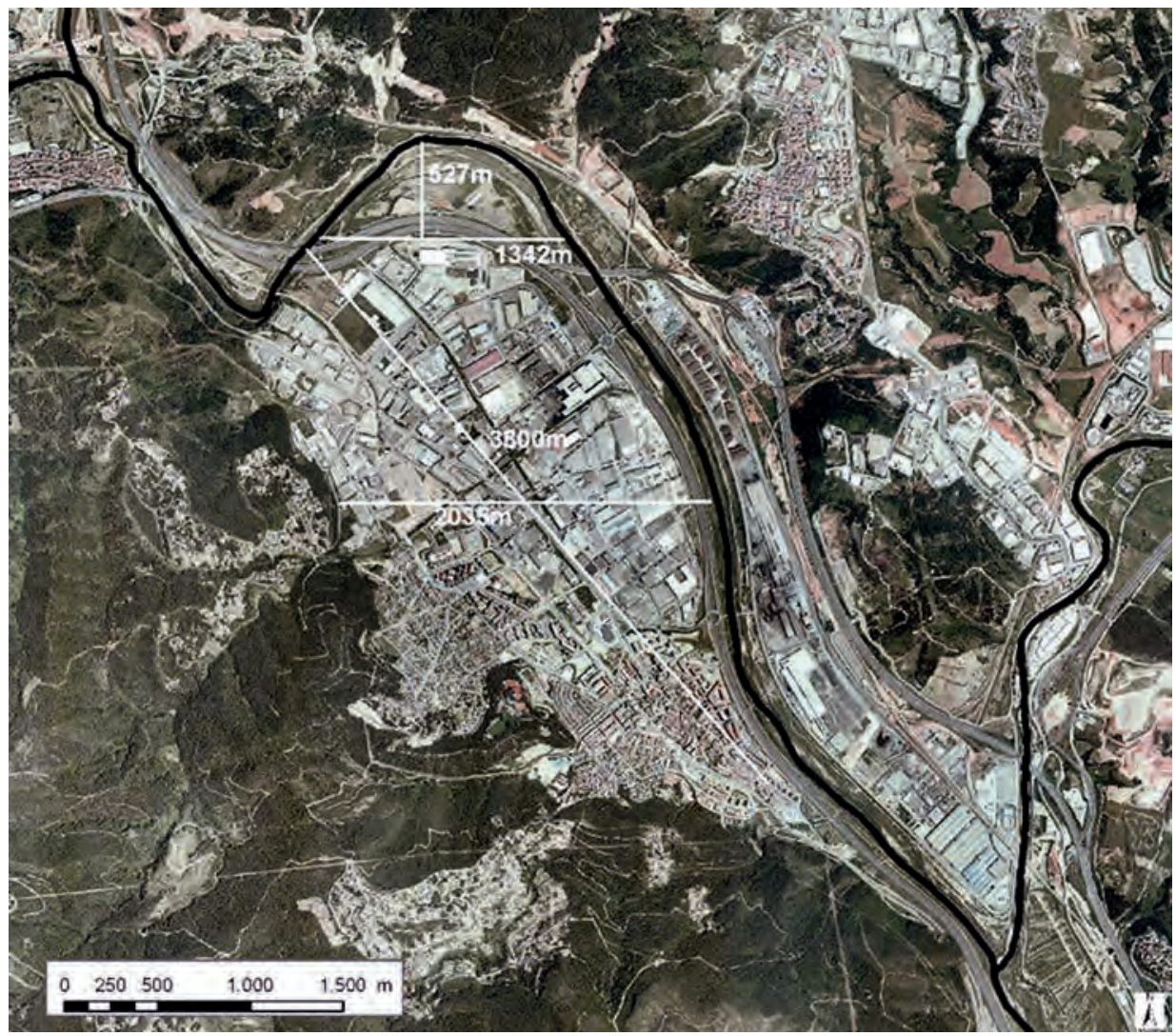

Figura 4. Morfometría básica de la hemicubeta de Sant Andreu de la Barca y del meandro de Ca n'Albareda. Nota: el trazo en negro corresponde a la red fluvial.

sión marina y conformaron las trazas del relieve actual. El movimiento de aguas provocó esfuerzos de distensión a nivel regional, que reforzaron las fracturas ya existentes y comportaron la aparición de otras fallas de distensión perpendiculares a las principales; éstas fueron la trabazón del conjunto que, más tarde, resultó levemente retocado por la regresión mesiniense y la transgresión pliocena. Así, la disposición del relieve debe comprenderse bajo dos particularidades bien definidas por los cambios isostáticos oligocenos y miocenos: por una parte la disposición general del relieve, que toma dirección NE-SW, y, por otra parte, el basculamiento orogénico, que implica cotas más elevadas hacia el NE y alturas inferiores hacia el SW. En otro orden de cosas es importante recalcar la importancia tectónica del sector Puig d'Agulles-Roc Forellac-Montcau, la existencia de una gran línea de fractura que se extiende desde Sant Andreu de la Barca hasta Vilanova i la Geltrú y la presencia de distintas macrofallas y microfallas asociadas que, precisamente desde Puig d'Agulles hasta Sant Andreu, se anastomosan para distenderse en la hemicubeta de Sant Andreu (fig. 4). 

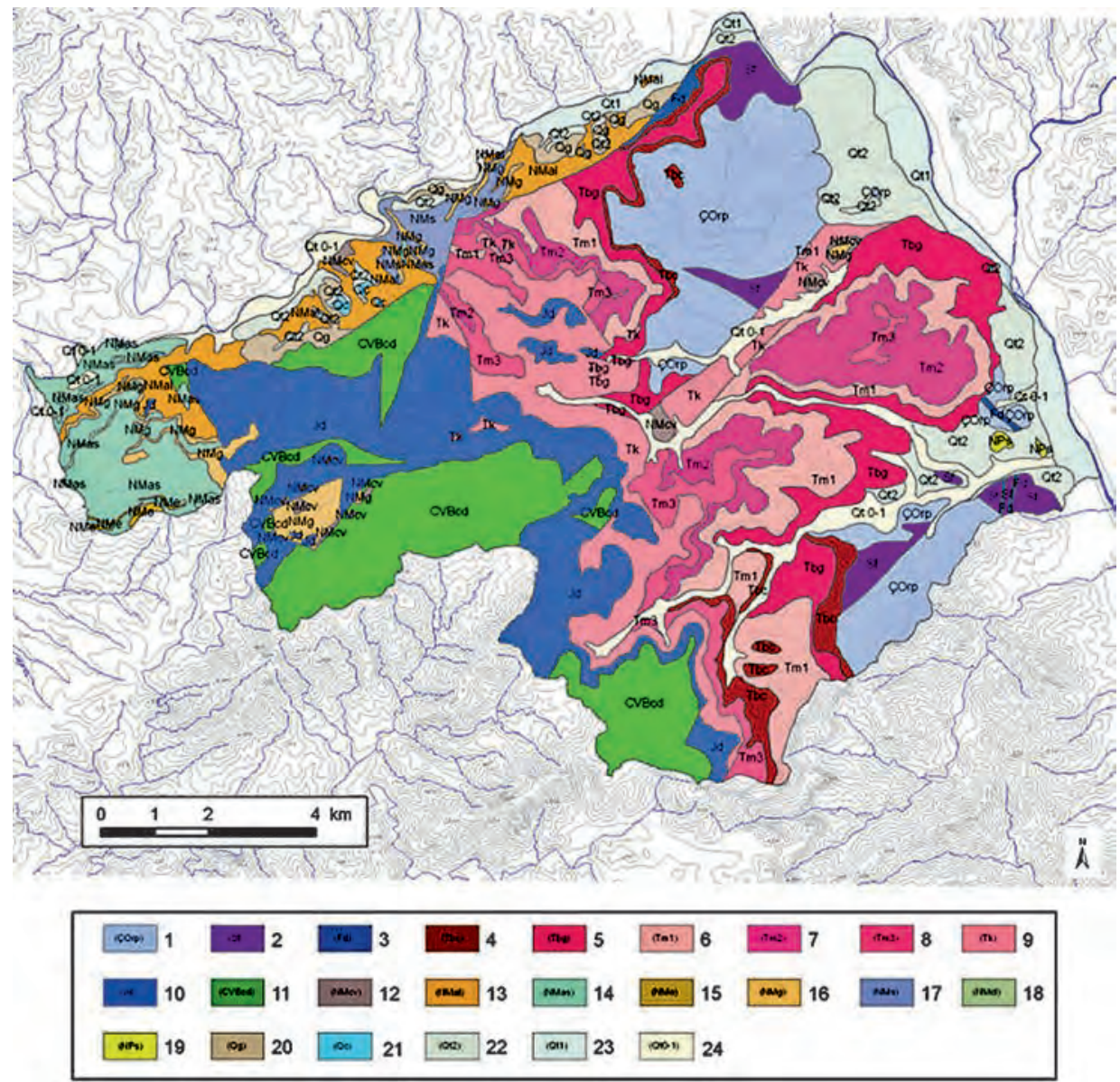

Figura 5. Materiales geológicos. Nota: reproducción tomada de Solé et al. (1975). Clave: 1. Pizarras micacíticas y pizarras (Cambroordoviciano), 2. Pizarras ampelíticas, filitas y sericitas (Siluriano), 3. Diques de posible diabasa (Carbonífero-Permiano), 4. Conglomerados silíceos basales (facies Buntsandstein), 5. Alternanza de areniscas silíceas y arcillas (facies Buntsandstein), 6. Calizas micríticas y dolomías (facies Muschelkalk inferior), 7. Areniscas y arcillas (facies Muschelkalk medio), 8. Dolomías y calizas (facies Muschelkalk superior), 9.

Lutitas y yesos versicolores (facies Keuper), 10. Dolomías y calizas (Jurásico-cretáceo inferior), 11. Calizas con intercalaciones dolomíticas (Valangariense-Barremiense), 12.

Conglomerados con matriz arcillosa (Aquitaniense-Burdigaliense), 13. Arcillas fosilíferas y limos (Burdigaliense-Serravaliense inferior), 14. Arcillas azules muy plásticas y arenas

(Serravaliense-Tortoniense), 15. Calcoarenitas arrecifales, biomicritas y biorruditas (Serravaliense-Tortoniense), 16. Areniscas de grano grueso localmente con conglomerados (Serravaliense-Tortoniense), 17. Arenas y arcillas de grano medio (Serravaliense-Tortoniense), 18. Calizas biomicríticas (Tortoniense), 19. Arenas y arcillas arenosas (Plioceno), 20. Pie de monte (derrubios de pendiente y facies proximales de abanicos aluviales (Pleistoceno), 21.

Costras de caliche (Pleistoceno), 22. Terraza fluvial. Gravas, arenas y lutitas (Pleistoceno terminal-Holoceno basal), 23. Terraza fluvial. Gravas, arenas y lutitas (Holoceno), 24. Lecho actual, llano de inundación ordinario y terraza más baja (Holoceno reciente). 
De este modo en la zona de estudio se identifican cuatro agrupamientos geológicos, correspondientes a la era Paleozoica y a los periodos Triásico, Cretácico y Cuaternario que, de manera más o menos evidente, se supeditan a las directrices de orientación y buzamiento NE-SW marcadas por el basamento primigenio (fig. 5).

El basamento de Muntanyes d'Ordal se conforma por materiales antiguos, de carácter paleozoico. Solé Sabarís y colaboradores (1975) distinguen tres niveles litológicos de entre los que destacan, por su abundancia, las pizarras y los esquistos del Cambro-Ordoviciano, que a menudo ofrecen gran profusión de diques cuarcíticos. A causa de la morfotectónica los materiales paleozoicos únicamente aparecen en el flanco oriental del sector.

Sobre la serie paleozoica se dispone una orla de materiales triásicos, que se establecen bien laminados sobre el Paleozoico y siguen un marcado buzamiento hacia el noreste. Por orden de antigüedad se acomodan seis pisos de facies germánica claramente estratificados: en la base se encuentran conglomerados ricos en cuarzo y areniscas y lutitas rojizas del Buntsandstein, siguen dolomías y calizas del Muschelkalk inferior, lutitas rojizas del Mulschelkalk medio con distintos niveles de yesos y, en los sectores más elevados y de manera irregular, dolomías, calizas y margas del Muschelkalk superior, así como arcillas versicolores y evaporitas del Keuper (Marqués, 1995). En algunos puntos los materiales del Buntsandstein presentan buenos ejemplos de alveolización, taffonitzación y otros ventifactos que, por asentarse sobre materiales rojizos, son cómodamente reconocibles. Los materiales del Muschelkalk y del Keuper, por otro lado, se localizan en los sectores más elevados del flanco este del área de estudio, siempre respetando el basculamiento paleozoico. Comúnmente muestran una gran horizontalidad y llegan a conformar relieves en cuesta de cierta extensión, fácilmente identificables por los cantiles escarpados de levante (fig. 6).

Sobre los materiales triásicos se dispone una cobertura de litologías cretácicas, también afectada por el basculamiento general, y con una distribución y un espesor creciente hacia el oeste. El roquedo se conforma en la base por dolomías del Jurásico y del Cretácico inferior, sobre las cuales se extiende una capa de calizas indiferenciadas; el profesor Llopis Lladó acostumbraba a definir esta cobertura como un "caparazón cretácico" sobre los materiales del Triásico y del Paleozoico. Como es habitual en este tipo de materiales, son abundantes las morfologías cársticas así como distintos ciclos de geoformas asociadas a la descomposición del roquedo.

Finalmente hay que referirse a la existencia de una película de materiales cuaternarios. Las formaciones más desarrolladas son de carácter aluvial, y se disponen cerca de los ríos Anoia y Llobregat, donde es posible distinguir diferentes terrazas fluviales y depósitos bien desarrollados de limos, arenas, gravas y guijarros de medida decimétrica; la mejor expresión de estas formaciones se pone de manifiesto en el meandro de Ca n'Albareda. Igualmente las formaciones coluviales también poseen cierta entidad, particularmente cuando se desarrollan en laderas acusadas, en comunión con materiales aluviales, en fondos de valle encajados o cuando se entremezclan con depósitos arcillosos miocenos (fig. 7). 


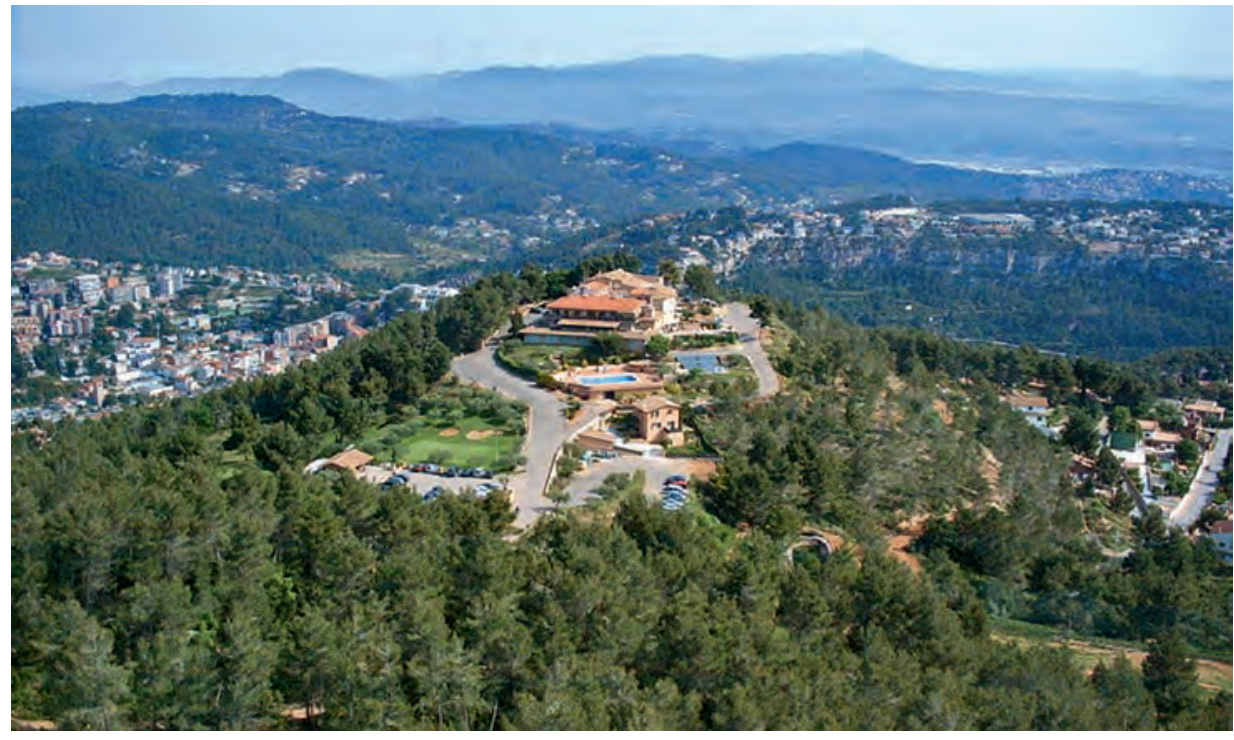

Figura 6. Los cantiles asociados a monoclinales sobre material calizo apenas representan 37 delimitaciones en el área de estudio, si bien su visibilidad se encuentra claramente manifiesta. En la imagen Can Rafel, frente a los acantilados de Els Carsos, Corbera de Llobregat.

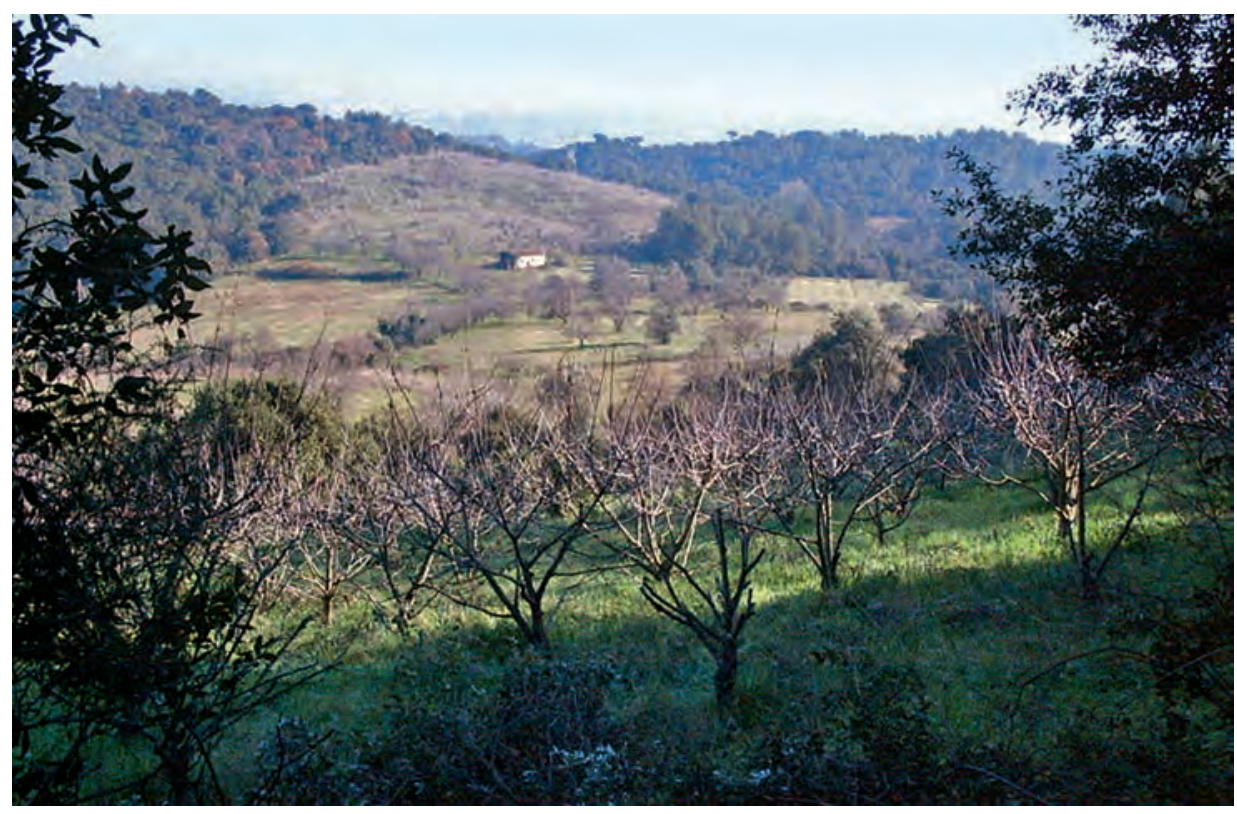

Figura 7. Los fondos de valle y las laderas de poca pendiente acogen materiales finos tradicionalmente aprovechados por su fertilidad agrícola. En la imagen llano de Sant Jaume, Castellví de Rosanes. 

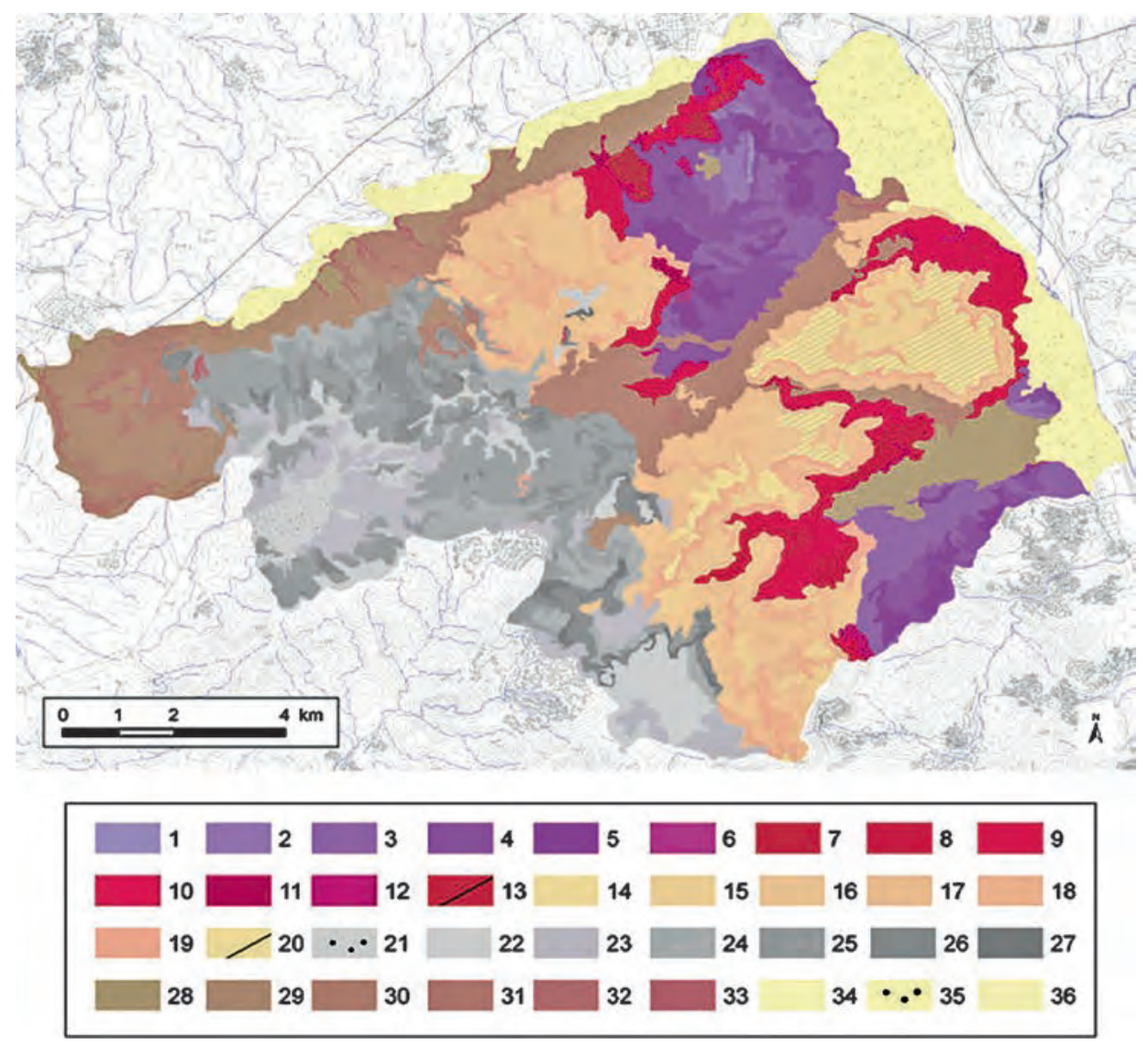

Figura 8. Unidades de relieve. Clave: 1. Rellano en material metamórfico, 2. Ladera de pendiente suave en material metamórfico, 3. Ladera de pendiente moderada en material metamórfico, 4.

Ladera de pendiente fuerte en material metamórfico, 5. Ladera de pendiente muy fuerte en material metamórfico, 6. Acantilado en material metamórfico, 7. Rellano en material detrítico del Triásico, 8. Ladera de pendiente suave en material detrítico del Triásico, 9. Ladera de pendiente moderada en material detrítico del Triásico, 10. Ladera de pendiente fuerte en material detrítico del Triásico, 11. Ladera de pendiente muy fuerte en material detrítico del Triásico, 12. Acantilado en material detrítico del Triásico, 13. Relieve en cuesta sobre material detrítico del Triásico, 14.

Rellano en material calizo del Triásico, 15. Ladera de pendiente suave en material calizo del

Triásico, 16. Ladera de pendiente moderado en material calizo del Triásico, 17. Ladera de pendiente fuerte en material calizo del Triásico, 18. Ladera de pendiente muy fuerte en material calizo del Triásico, 19. Acantilado en material calizo del Triásico, 20. Relieve en cuesta sobre material calizo del Triásico, 21. Llano en material calizo del Cretácico, 22. Rellano en material calizo del Cretácico, 23. Ladera de pendiente suave en material calizo del Cretácico, 24. Ladera de pendiente moderada en material calizo del Cretácico, 25. Ladera de pendiente fuerte en material calizo del Cretácico, 26. Ladera de pendiente muy fuerte en material calizo del Cretácico, 27. Acantilado en material calizo del Cretácico, 28. Llano en material margocalizo, 29. Ladera de pendiente suave en material margocalizo, 30. Ladera de pendiente moderada en material margocalizo, 31. Ladera de pendiente fuerte en material margocalizo, 32. Ladera de pendiente muy fuerte en material margocalizo, 33. Acantilado en material margocalizo, 34. Lecho de río, 35. Llano en material aluvial, 36. Ladera de pendiente suave en material aluvial. 
[3]

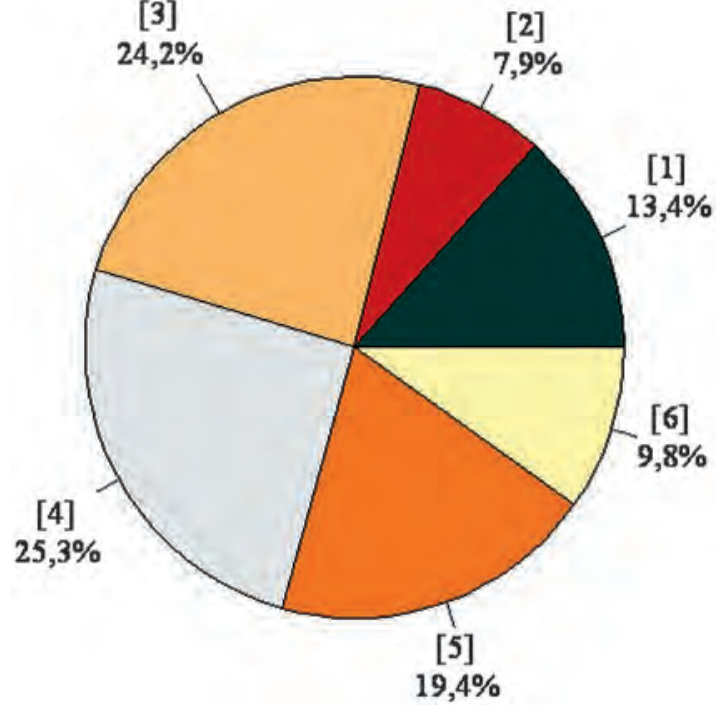

Figura 9. Superficie ocupada por grupo de material. Clave:

1. en material metamórfico;

2. en material detrítico de Triásico;

3. en material calizo del Triásico;

4. en material calizo del Cretácico;

5. en material margocalizo;

6. en material aluvial.

\section{Resultados}

El método aplicado ha generado una clasificación de 55 combinaciones posibles simplificada a 49 unidades de relieve probables, de las cuales únicamente 36 llegan a tener una correspondencia real sobre el territorio. Como es lógico la participación de cada una de estas delimitaciones es desigual, existiendo categorías muy bien representadas desde el punto de vista del alcance superficial, el número y la distribución de unidades, y otras categorías que presentan una extensión, un número o una corología mucho más irregular (fig. 8).

En cuanto a extensión la clase mejor representada son las unidades de relieve sobre material calizo del Cretácico (25.33\% de la superficie total), seguidas de cerca por las unidades sobre material calizo del Triásico (24.24\%). En otro orden se encuentran aquellas otras delimitaciones desarrolladas sobre material margocalizo (19.43\%), sobre litologías metamórficas $(13.35 \%)$ y sobre material detrítico del Triásico (7.86\%). Las unidades desarrolladas sobre material aluvial representan un $9.79 \%$ de la superficie del área de estudio (fig. 9). La distribución de estas delimitaciones es solidaria con los rasgos litológicos y el buzamiento del sector; así, las unidades desarrolladas sobre material aluvial se localizan en las vegas del Anoia y el Llobregat, las unidades sobre material metamórfico se encuentran más desarrolladas en el basamento del margen nororiental y la orla del Buntsandstein entre éstos y las litologías calizas.

En todos los casos las formas del relieve más abundantes son las laderas, que llegan a comportar prácticamente un $76 \%$ del total de unidades de relieve identificadas. Por clases las unidades de mayor extensión se desarrollan sobre material cretácico (26.36\%), acompañadas de aquellas otras sobre material calizo del Triásico (25.53\%). La mayoría 


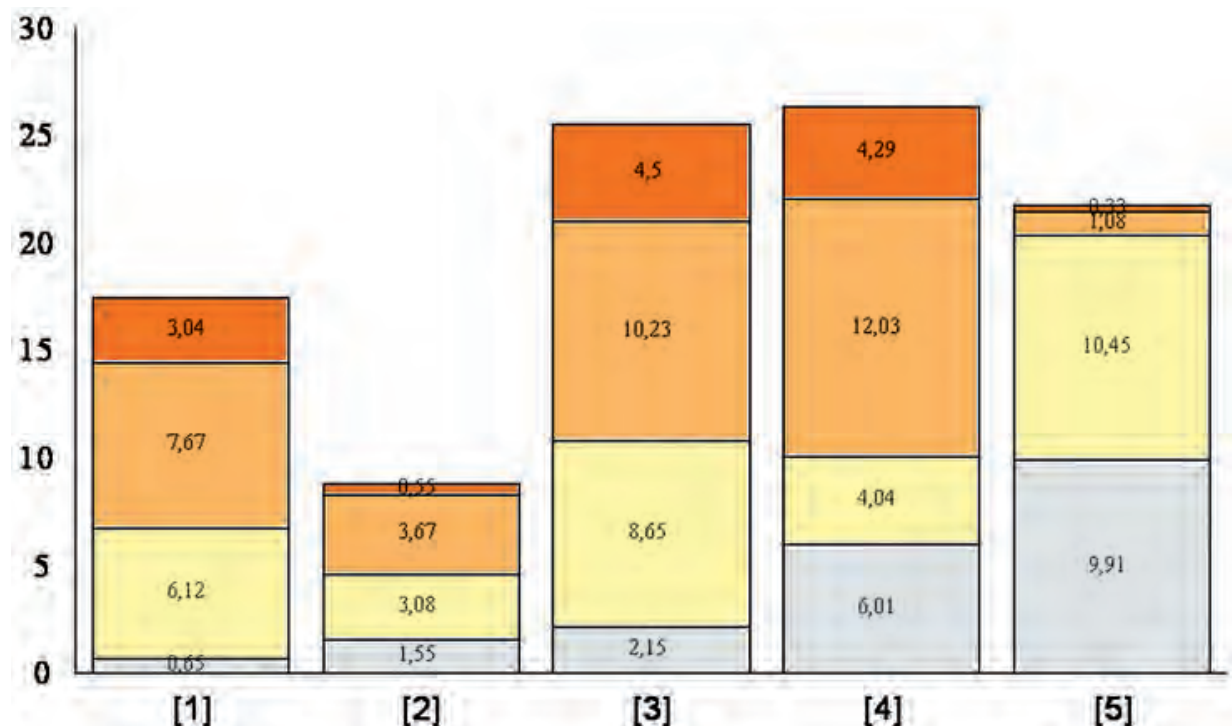

Figura 10. Superficie ocupada por grado de pendiente y grupo de material (\%). Clave: 1. en material metamórfico; 2. en material detrítico del Triásico; 3. en material calizo del Triásico; 4. en material calizo del cretácico; 5. en material margocalizo. Nota: la disposición de los grados de pendiente sigue una secuencia lógica de abajo hacia arriba: pendiente suave, moderada, fuerte y muy fuerte.

de laderas posee una pendiente fuerte (en el caso de las unidades sobre material cretácico esto es un $45.64 \%$ de la superficie ocupada por el grupo) seguido de moderado $(34,80 \%$ en el caso de las unidades sobre material detrítico del Triásico). Únicamente en el caso de las unidades desarrolladas sobre material margocalizo toman mayor importancia las laderas de pendiente moderado y suave $(10.45 \%$ y $9.91 \%$ de la superficie del grupo, respectivamente), sin duda a causa de la debilidad y poca resistencia de este sustrato (fig. 10). En otro orden de cosas conviene realizar una pequeña referencia a los acantilados que, aunque estrictamente no forman parte de una ladera, sí participan notablemente en la percepción de ésta, aparte de constituir, también, hitos indiscutibles del relieve. En efecto, la superficie ocupada por acantilados alcanza, con 86 delimitaciones, prácticamente el 3\% de Muntanyes d'Ordal. La clase mejor representada atiende a acantilados sobre material calizo triásico (53.22\%), seguido de unidades sobre material detrítico triásico (22.11\%) y sobre litologías cretácicas (18.98\%). A pesar de que el significado de las unidades sobre materiales metamórficos y margocalizos es notorio, su participación relativa en el conjunto es bastante moderada (fig. 11).

\section{Discusión}

El método utilizado permite evidenciar la importancia del relieve en el paisaje y, particularmente, en su zonificación bajo un prisma geomorfológico. El procedimiento 


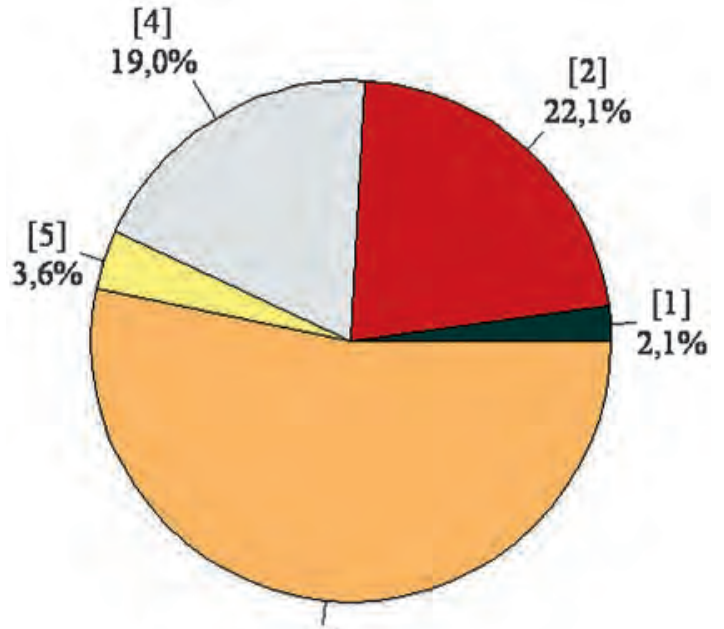

[3]

$53,2 \%$
Figura 11. Superficie ocupada por acantilados y grupo de material. Clave: 1. en material metamórfico; 2. en material detrítico del Triásico; 3. en material calizo del Triásico; 4. en material calizo del Cretácico; 5. en material margocalzo.

seguido es de gran simplicidad; se basa en la identificación, la individualización y la posterior correlación de aquellas variables que, lato senso, configuran el paisaje desde la perspectiva del relieve. Esta sencillez de aplicación, sin embargo, comporta un esfuerzo de análisis, primero, y síntesis, después, que toma especial valor cuando se realiza de manera sistemática y respetando unas nociones escalares básicas. El resultado se materializa en una zonificación cartografiable de gran sintetismo y carácter holístico, propia de los inventarios territoriales y con valor para la caracterización del paisaje desde el punto de vista del relieve. Este procedimiento, sin embargo, conlleva ciertas dificultades a tener presente, a saber: los problemas inherentes a la zonificación por parámetros, la dificultad para establecer un límite preciso entre unidades, la relatividad de la caracterización de unidades, la obligatoria necesidad de conocer la aplicación de las unidades antes de inventariarlas y la engañosa significación visual de la zonificación realizada.

Las zonificaciones realizadas por parámetros presentan la ventaja de su sistematicidad, hecho que reduce la ambigüedad habitualmente criticada de las unidades de paisaje. Sin embargo este método implica un conocimiento elevado de todas las variables a inventariar, una correlación de las mismas y, frecuentemente, una posterior simplificación. Todas estas tareas requieren una dedicación importante, que no siempre se encuentra reconocida en el resultado final del estudio. En el caso de nuestro ejercicio los datos recogidos indicaron una clasificación inicial de 55 categorías posibles, que finalmente quedó reducida a 36 categorías con una delimitación efectiva sobre el territorio.

El trazado del límite entre unidades es un problema habitual en cualquier zonificación (Fenneman, 1916), incluso si se trabaja a una escala prefijada. Talmente las unidades sobre material detrítico del Triásico son fácilmente perceptibles a causa de su cromatismo y, por lo tanto, las 47 delimitaciones propuestas, a pesar de comportar menos 


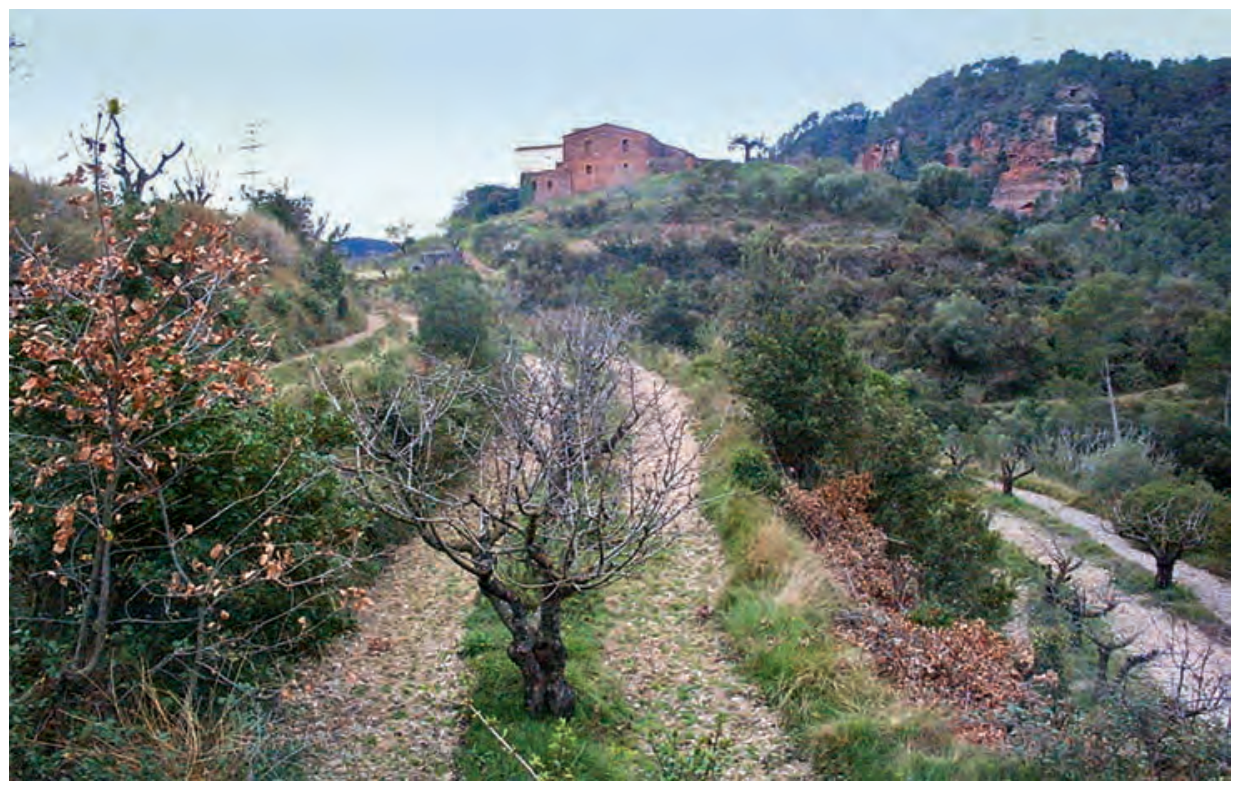

Figura 12. Las facies Buntsandstein son fácilmente reconocibles a causa de su coloración rojiza. En la imagen contraste entre materiales esquistosos del Cambro-Ordiviciano y cantiles detríticos del Triásico, en los contornos de Can Riera, Cervelló.

de un $8 \%$ del conjunto, resultan netamente diferenciables (fig. 12). No ocurre lo mismo, por ejemplo, con las unidades sobre material margocalizo, donde la pendiente no siempre es una variable fidedigna, los parámetros edáficos son muy variables y la coloración confusa pues, de las 51 delimitaciones propuestas (un 19.43\%) aquellas que se encuentras a poniente son de tonalidades ocres y parduscas, mientras que aquellas de levante, a medida que el transporte y oxidación de los materiales ha sido mayor, son más rojizas.

Por otra parte hay que contemplar dificultades para caracterizar las unidades, ya que éstas, después de considerar los elementos topográficos, litológicos y geomorfológicos comunes, verdaderamente toman sentido cuando recogen aquellos aspectos de carácter singular. Determinadas geoformas son ciertamente habituales, como es el caso de alveolos, taffonis y ventifactos en general; otras, caso de ciertas formaciones cársticas, son más difíciles de detectar y describir, como sucede con alveolos de disolución o pequeñas cavidades y simas con presencia de espeleotemas en distinto grado de desarrollo. En otros casos los aspectos realmente distintivos son totalmente singulares, como sucede con ciertas manifestaciones de relieve montserratino, reflejadas por la toponimia local con designaciones tan representativas como Roca Dreta o Roques Tortes. Todo ello comporta dificultades a la hora de sistematizar resultados y realizar valoraciones.

Una de las mayores utilidades que revisten las zonificaciones de este tipo se encuentra en la posterior utilización que se realice de ellas. Para que esta aplicación pueda ser pro- 
vechosa es necesario realizar un esfuerzo de previsión importante, ya que cualquier información que se utilice se ha de colectar durante el inventariado de datos. Por ejemplo, con la intención de realizar un estudio sobre la tapiología de determinadas construcciones del sector se tuvo que recoger información sobre el cromatismo del roquedo (bien visible en el material del Trias) pero también sobre su friabilidad, como resulta en las 46 delimitaciones sobre material metamórfico.

La percepción visual de las unidades y la impronta fisionómica que ejercen en el espectador no siempre se corresponden con su significado real y con la participación que ejercen en el conjunto. Así, por ejemplo, uno de los aspectos que más identidad otorga a las unidades son los acantilados asociados a monoclinales calizos triásicos, que se disponen a modo de cornisa por la mayor parte del dorso de la cuesta, a modo de escarpe por el frente de la cuesta y, en menor medida, por el dorso de capa. Estos cantiles con esfuerzo alcanzan el 1,6\% del conjunto, si bien el número de unidades (37), la verticalidad y la disposición de éstos aseguran una gran visibilidad. En otro orden de cosas se encuentran las unidades de relieve sobre material aluvial, que ocupan menos del 10\% de la superficie de Muntanyes d'Ordal, y se materializan en ocho grandes delimitaciones en la vega de los ríos Anoia y Llobregat. Las unidades desarrolladas sobre superficies llanas contribuyen en un 7,80\% de la extensión del conjunto, mientras que el espacio afectado por el lecho del río, en el sentido estricto de la acepción geomorfológica, apenas se cifra en un 1,32\%. El aprovechamiento agrícola, urbano e industrial de estos sectores ha desfigurado notablemente su morfología original. Un buen ejemplo de ello es el meandro de Ca n'Albareda (figura 4), que encuentra un origen estructural en la distensión provocada por el sistema de fallas Vilanova-Sant Andreu en su contacto con la falla del Llobregat; estos esfuerzos provocaron la fractura del sector y la posterior aparición de una fosa tectónica de relativa importancia que, como consecuencia de los movimientos miocenos y pliocenos, terminó desgajándose para formar dos hemicubetas distanciadas poco más de $2.000 \mathrm{~m}$. El río Llobregat, que entra en este ámbito tras salvar el congosto de Martorell, ha aprovechado la horizontalidad del relieve para decantar buena parte de su carga sedimentaria, dando lugar a un anastomosamiento del cauce fluvial. Una buena muestra de ello es que el lugar fue utilizado desde antiguo para unir ambas orillas del Llobregat, tal y como demuestra tanto el actual topónimo de Sant Andreu de la Barca, como el antiguo nombre de la población, Sant Andreu d'Aigüestoses.

\section{Conclusiones}

La importancia del relieve en la conformación de determinados paisajes es notoria. Ello se debe a que el relieve supedita o, cuanto menos, condiciona otros elementos estructurantes del paisaje como es el caso, por ejemplo, de la vegetación o de las actividades humanas. Según el planteamiento de estudio que se adopte, y de manera independiente de la realidad del área de trabajo, se pueden realizar ejercicios desde tres vías metodológicas, atendiendo al relieve como elemento condicionante, como elemento estructurador o como elemento definidor del estudio de paisaje. 
En Muntanyes d'Ordal la morfoestructura y la historia geológica participan de manera especialmente significativa en la conformación del relieve. Con el propósito de desgranar aquellos aspectos del relieve de mayor importancia en la caracterización del paisaje se ha realizado una zonificación, que tiene por objetivo sintetizar y homogeneizar los rasgos de índole topográfico, geológico y geomorfológico de mayor significado en el paisaje. En esta tarea el relieve se ha entendido como elemento definidor del estudio de paisaje, y se ha aplicado un método propio de los inventarios territoriales.

Para Muntanyes d'Ordal se han distinguido seis grandes grupos de sustrato, cinco grandes formas de relieve, cuatro posibles grados de pendiente para las laderas y cinco familias de geoformas, aparte de una última categoría abierta. De ello deriva una clasificación teórica con 55 combinaciones posibles que, finalmente, se ha reducido a 36 delimitaciones efectivas. La mayor parte de éstas hace referencia a superficies en laderas de pendiente fuerte en material calizo del Cretácico, laderas en pendiente moderado y suave en material margocalizo, y laderas en pendiente fuerte y moderado en material calizo del Triásico. Por su significación visual y su participación en el paisaje también son de interés las áreas de acantilados, particularmente aquellas desarrolladas sobre material detrítico del Triásico.

Finalmente cabe decir que por su alto valor fisiognómico los estudios de este tipo presentan un gran interés para realizar caracterizaciones territoriales, trabajos de ordenación y planificación del territorio, zonificaciones de aptitud de usos o estudios de geodiversidad.

\section{Agradecimientos}

Durante el redactado de este artículo se ha contado con el apoyo institucional del Servei de Gestió i Evolució del Paisatge de la Universidad de Barcelona. La información aquí expuesta es fruto de una investigación de mayor alcance desarrollada bajo dirección del Dr. Antonio Gómez Ortiz.

\section{Referencias bibliográficas}

Bolòs, M. (1992). Manual de ciencia del paisaje. Masson, 273 pp., Barcelona.

Chevalier, M. (1928). El paisatge de Catalunya. Barcino, 197 pp., Barcelona.

Christian, C. S., Stewart, G. A. (1968). Methodology of integrated surveys. En: Aerial surveys and integrated studies (AA.VV.). UNESCO, pp. 233-281, Paris.

Fenneman, N. (1916). Physiographic subdivisión of the United States. Annals of the Association of American Geographers, pp. 17-22. [Disponible en: http://www.pnas.org/ content/3/1/17.full.pdf?ck=nck].

García Quintana, A., García Hidalgo, J. F., Martín Duque, J. F., Pedraza Gilsanz, J., GONZÁLEZ MARTín, J. A. (2004). Geological factors of the Guadalajara landscapes 
(Central Spain) and their relevance to landscape studies. Landscape and urban planning, 69: 417-435.

Garzón Heydt, G. (1988). Geología y zonificación de unidades territoriales. En: Geología ambiental (Ayala, F. J., Jordà, J. F., Eds.). ITGE, pp. 231-238, Madrid.

Gómez OrTIZ, A. (2001). El necesario equilibrio entre preservación y explotación del paisaje: el caso del Principado de Andorra. Geocrítica, 103. [Disponible en: http:// www.ub.es/geocrit/sn-103.htm].

Gray, M. (2004). Geodiversity. Valuing and conserving abiotic nature. Wiley, 434 pp., Chichester.

Hansen Machín, A. (1993). El paisaje de Bandama y su entorno. Cabildo Insular de Gran Canaria, 127 pp., Las Palmas de Gran Canaria.

HeRnÁNDEZ PACHECO, E. (1934). El paisaje en general y las características del paisaje hispano. Academia de Ciencias Exactas, Físicas y Naturales, 64 pp., Madrid.

Hernández Pacheco, E. (1955). Fisiografía del Solar Hispano. Academia de Ciencias Exactas, Físicas y Naturales, 665 pp., Madrid.

KNIGHT, J. (2000). Geology, glaciation and the development of landscape "character" on Ireland. Geology today, 16: 148-153.

Llopis Lladó, N. (1947). Contribución al conocimiento de la morfoestructura de los Catalánides. Ariel, 372 pp., Barcelona.

MArqués, A. (1995). La Geología. En: Atles del Baix Llobregat (Miranda, J., Dir.). Institut Cartogràfic de Catalunya, Barcelona.

Marthaler, M. (2004). Lecture et analyse d'un paysage: Zermatt et le Cervin. Un exemple de la mémoire de la terre révelée par les panoramas. En: Paysages géomorphologiques (Reynard, E., Pralong, J., Eds.). Travaux et Recherches, 27. Lausana.

MARTín DuQue, J. F. (2000). La información geomorfológica en el contexto de los inventarios ambientales. Mapas fisiográficos para la gestión territorial. Boletín de la Real Sociedad Española de Historia Natural (Sección de Geología), 96 (1-2): 33-46.

Mitchell, C. (1991). Terrain evaluation. Longman, 441 pp., Londres.

MMA (ed.) (2004). Guía para la elaboración de estudios del medio físico. Ministerio del Medio Ambiente, 809 pp., Madrid.

Paül, V., Serrano, D. (2005). Muntanyes d'Ordal. El nom que no surt als mapes. Publicacions de l'Abadia de Montserrat, 120 pp., Barcelona.

Pedraza Gilsanz, J., Garzón Heydt, G. (1978). Bases geológicas y geomorfológicas para la sistematización de los anàlisis del medio físico. Boletín informativo del Medio Ambiente de la CIMA, 8: 51-70.

Peña Monné, J. L. (ed.) (1997). Cartografía geomorfológica. Editorial Geoforma, 227 pp., Logroño. 
REYNARD, E. (2004). La géomorphologie et la création des paysages. En: Paysages géomorphologiques (Reynard, E., Pralong, J., Eds.). Travaux et Recherches, 27. Lausana.

REYNARD, E. (2005). Paysage et géomorphologie: quelques réflexions sur leurs relations réciproques. En: La polyphonie du paysage (Droz, Y., Miéville-Ott, V., dir.). Presses polytechniques et universitaires romandes, pp. 101-124, Lausana.

REYNARD, E. (2006). Fiche d'inventaire des géomorphosites. [Disponible en: http:// www.unil.ch/igul/ page17893.html].

SÁNChez DíAz, J. (dir.) (1995). Cartografía del medio natural de Gran Canaria. Cabildo Insular de Gran Canaria, Universitat de València, Universidad de Las Palmas de Gran Canaria, 165 pp., Las Palmas de Gran Canaria.

Serrano Cañadas, E., González Trueba, J. J. (2005). Assessment of geomorphosites in protected natural areas: the Picos de Europa National Park (Spain). Geomorphologie, 3: 197-208.

Solé Sabarís, L. (dir.) (1975). Hoja 420. Hospitalet de Llobregat. Mapa geológico de España 1:5000. Servicio de Publicaciones del Ministerio de Industria, Madrid.

TRICART, J. (1976). Leyenda para el mapa geomorfológico de Francia (1: 50000). Instituto Jaume Almera, Barcelona, 69 pp.

TRICART, J., KILIAN, J. (1982). La eco-geografía y la ordenación del medio natural. Anagrama, 288 pp., Barcelona. 